her: miscarriages before she worked in lead. All four had never lost a single day's work through ill-health in their lives. Although the number of married women working in lead was small I have ventured to tabulate them in the same way as the wives of the male operatives. Tables VII. $(a)$ and VII. $(b)$ will correspond respectively to Tables VI. $(a)$ and VI. $(b)$.

TABLE VI. (b).-Showing the Number of Pregnanoies and Miscarriages in Lead-workers' Wives who have Aborted.

\begin{tabular}{|c|c|c|c|c|c|c|}
\hline $\begin{array}{l}\text { Number of years } \\
\text { married. }\end{array}$ & 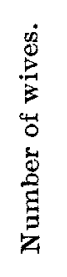 & 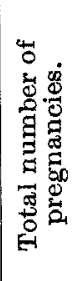 & 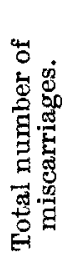 & 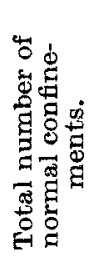 & 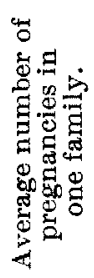 & 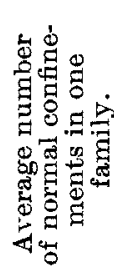 \\
\hline Over 30 years $\quad \ldots$ & 3 & 35 & 6 & 29 & $11 \cdot 6$ & $9 \cdot 6$ \\
\hline Between 20 and 30 years & 6 & 52 & 10 & 42 & $8 \cdot 6$ & $7 \cdot 0$ \\
\hline , 15,20 & $\left\{3^{*}\right.$ & 25 & 5 & 20 & $8 \cdot 3$ & $6 \cdot 6$ \\
\hline & $(5$ & 33 & 8 & 25 & $6 \cdot 6$ & $5 \cdot 0$ \\
\hline 10,15, & $1^{*}$ & 8 & 1 & 7 & $8 \cdot 0$ & $7 \cdot 0$ \\
\hline 3 & 4 & 24 & 7 & 17 & $6 \cdot 0$ & 42 \\
\hline " 5,10, & 4 & 19 & 4 & 15 & $4 \cdot 7$ & 3.7 \\
\hline$" 2,5$, & 4 & 12 & 4 & 8 & $3 \cdot 0$ & $2 \cdot 0$ \\
\hline Under 2 years $\quad \ldots \quad \ldots$ & - & - & - & - & & - \\
\hline
\end{tabular}

* In these cases the miscarriages took place before the husbandi commenced to work in lead.

TABLE VII. (a).-Showing the Number of Pregnancies $2 n$ Women working in Lead.

\begin{tabular}{|c|c|c|c|c|c|}
\hline \multirow{2}{*}{$\begin{array}{l}\text { Number of years } \\
\text { married. }\end{array}$} & \multirow{2}{*}{ 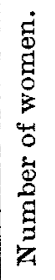 } & \multirow{2}{*}{ 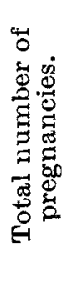 } & \multicolumn{2}{|c|}{$\begin{array}{l}\text { Number of pregnancies } \\
\text { in one family. }\end{array}$} & \multirow{2}{*}{ 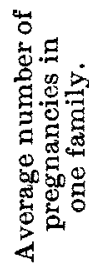 } \\
\hline & & & Maximum. & Minimum. & \\
\hline Over 30 years $\ldots \begin{array}{lll}\ldots & \ldots & \ldots\end{array}$ & 2 & 18 & 11 & 7 & $9 \cdot 0$ \\
\hline Between 20 and 30 years... & 5 & 22 & 7 & 0 & $4 \cdot 4$ \\
\hline " $\quad 15,20 \quad, \quad \ldots$ & 6 & 21 & 6 & 1 & $3 \cdot 5$ \\
\hline$" 10,15, \quad, \quad \ldots$ & 2 & 0 & 0 & 0 & 0 \\
\hline$, \quad 5,10,1, \ldots$ & 7 & 11 & 4 & 0 & $1 \cdot 5$ \\
\hline , $\quad 2, \quad 5 \quad, \quad \ldots$ & 6 & 11 & 3 & 1 & $1 \cdot 8$ \\
\hline $\begin{array}{llll}\text { Under } 2 \text { years } & \ldots & \ldots & \ldots\end{array}$ & 9 & 5 & 2 & 0 & 0.6 \\
\hline
\end{tabular}

TABLE VII. (b).-Showing the Number of Pregnancies and Miscarriages in Women working in Lead who have Aborted.

\begin{tabular}{|c|c|c|c|c|c|c|}
\hline $\begin{array}{c}\text { Number of years } \\
\text { married. }\end{array}$ & 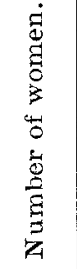 & 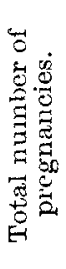 & 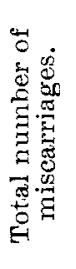 & 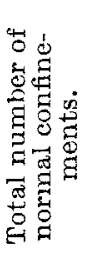 & 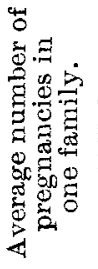 & 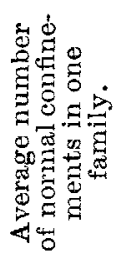 \\
\hline & $1^{*}$ & 6 & 1 & 5 & $6 \cdot 0$ & $5 \cdot 0$ \\
\hline Over 30 years $\quad \ldots$ & $\{1$ & 2 & 1 & 1 & $2 \cdot 0$ & $1 \cdot 0$ \\
\hline Between 20 and 30 years & 1 & 4 & 2 & 2 & $4 \cdot 0$ & $2 \cdot 0$ \\
\hline & $1^{*}$ & 4 & 1 & 3 & $4 \cdot 0$ & $3 \cdot 0$ \\
\hline , 15,20, & $\{4$ & 28 & 6 & 22 & $7 \cdot 0$ & $5 \cdot 4$ \\
\hline 10,15 & $5^{*}$ & 27 & 5 & 22 & $5 \cdot 4$ & $4 \cdot 4$ \\
\hline$" 10, " 10$, & 5 & $?$ & $?$ & 12 & $?$ & $2 \cdot 4$ \\
\hline$., 5,10$, & - & - & - & 一 & - & - \\
\hline " $2,5 \quad$, & - & - & - & - & - & - \\
\hline Under 2 years $\quad \ldots \quad \ldots$ & - & - & - & - & 一 & - \\
\hline
\end{tabular}

* In these cases the miscarriage took place before the mothers commenced to work in leas.

Final conolusions. - After giving each case which has come under my observation full consideration I have come to the following conclusions:-

1. That of the 527 lead-workers I only met with one case of lead-poisoning.

2. That individual symptoms, which at first sight might have been attributed to lead-poisoning, were found upon closer examination to be due to other causes.

3. That the health record of the lead-workers was excellent (the complaints I have mentioned are for the most part only minor ailments). Of 348 men 196 have not lost a single day's work through ill-health from any cause whatever since they commenced to work in lead, and the same may be said of 90 out of 124 single women ; 26 out of 55 married women have only been absent through confinements.

4. That the general condition of the work-people was good and would compare favourably with that of a like number of workers in any average healthy trade.

5. That the 91 operatives who had worked in lead for over 20 years were not suffering any ill-effects from their employment, although they had worked for years under practically no regulations.

6. That it must always be remembered that lead-workers are subject to the common ailments of life just in the same way as other people.

Newcastle-under-Lyme.

\section{ACUTE DILATATION OF THE STOMACH, WITH ILLUSTRATIVE CASES. ${ }^{1}$}

BY H. CAMPBELL THOMSON, M.D., M.R.C.P. LOND. AsSISTANT PHYSICIAN AND PATHOLOGIST TO THE MIDDLESEX HOSPITAL.

ACUTE dilatation of the stomach is characterised by its sudden onset, by the vomiting of enormous quantities of fluid, and by very severe general symptoms, which in the recorded cases have always ended fatally within a few days after the first onset of the disease. The condition was first fully described by Dr. Hilton Fagge ${ }^{2}$ who recorded four cases, two of which had come under his own personal observation. Since then a case has been recorded by Mr. Henry Morris, ${ }^{3}$ but beyond these the subject does not appear to have attracted much attention. I have during the past three years made postmortem examinations upon four cases in which death was immediately due to this condition, and I believe that the disease, though of course very uncommon, is not so rare as has generally been supposed, and that probably the difference between the very serious cases and the less severe forms of dilatation, also acute, which not infrequently accompanies severe illnesses, is one of degree rather than of kind. Before referring to the cases recorded by others $I$ will give a brief account of those which have come under my own notice, and I must here acknowledge my indebtedness to Mr. Henry Morris and Dr. Kingston Fowler who have kindly allowed me to make use of the clinical notes of cases which have been under their care. The first case is one in which acute dilatation suddenly supervened upon chronic dilatation, the latter being due to a growth of the pylorus.

CASE 1. - The patient was a man, aged 48 years, who was admitted into the Middlesex Hospital on Oct. 31st, 1899, under the care of Dr. Kingston Fowler. Symptoms had existed for three months before admission, the chief being discomfort after food and frequent vomiting. On admission the patient was found to be considerably emaciated; the stomach was dilated and extended downwards to about an inch above the umbilicus; no splash was obtained. An indefinite tumour could be felt in the epigastrium. The pulse was 84, regular, and the patient, considering the disease he was suffering from, did not appear to be unduly ill, and certainly presented no immediate symptoms of an alarming character. On Nov. 3rd-i.e., three days after admission-the stomach was washed out in order to relieve the vomiting, which occurred at intervals and which in no way differed from that which usually takes place in cases of pyloric cancer. On this occasion 38 ounces were drawn off with a soft syphon tube. The patient expressed himself as feeling relieved by

1 A paper read before the Royal Medical and Chirurgical Society on Oct. 22nd, 1901

2 Guy's Hospital Reports, 1872-73.

3 Transactions of the Pathological Society of London, vol, xxxiv. 
the washing, and the process was repeated on the following morning (the 4th), no vomiting having occurred in the interval. Relief was again obtained and the patient was able to take about half a pint of beef-tea and a very little pudding at midday. Suddenly, during the afternoon, a change for the worse took place, which was ushered in by slight hiccough, accompanied by abdominal pain and uneasiness, which the patient attributed to flatulence; at 6 P.M. the pain was considerable; at 8 P.M. he vomited about eight ounces of thick, dark brown fluid; and an hour later ( 9.15 P. M.) he was very collapsed, with a feeble pulse of 120 , a subnormal temperature, and cold extremities. There was now severe abdominal pain, the outline of the stomach was easily seen, and appeared to cover a greater area than formerly ; there was no muscular rigidity, but the abdominal walls did not appear to move with respiration. In the face of these acute symptoms it was thought possible that a perforation of the stomach might have taken place. A quarter of a grain of morphia was given hypodermically and hot bottles were put to the feet; no food was given by the mouth. About midnight the patient was very wakeful, but slept after a second injection of morphia. The next day (the 5 th) the patient was drowsy but said he had no pain; the pulse was 120 and the abdomen moved slightly with respiration; the lower border of the stomach now reached the umbilicus and a tympanitic percussion note could be obtained in the left axilla as high as the fourth rib. Nourishment was given by nutrient enemata and suppositories, which were retained. The general condition remained about the same all day, but towards evening he became more collapsed and at $6 \mathrm{P}$. M. a hypodermic injection of strychnine was given. The abdomen, however became more distended. Death took place at $2.55 \mathrm{~A} . \mathrm{M}$. on the morning of the 7th. During the acute illness the urine had become very scanty, none at all was passed from 1 A.M. till midnight on the 5th, when a catheter was passed, but only one ounce was drawn off. At the post-mortem examination the contents of the abdomen were almost entirely obscured by the dilated stomach, which was tightly distended with gas and also contained a considerable quantity of dark brown fluid. In shape the stomach was cylindrical, the lesser curvature making a sharp curve, while the greater curvature was rounded and reached a point just below the level of the iliac crest. There was a growth of the pylorus which considerably narrowed the orifice.

This case, then, is an example of acute dilatation suddenly supervening upon a chronic one; owing to the stricture the stomach had, no doubt, for some time had a considerable strain put upon it, and then suddenly acute dilatation set in. Possibly the slight irritation produced by washing out the stomach may have upset the balance or, and what I think is more likely, the growth may have implicated some of the nervous structures in the neighbourhood.

The second case occurred after an exploration of the kidney.

CASE 2.-The patient, a man, aged 26 years, was admitted under the care of Mr. Henry Morris with symptoms pointing to the presence of renal calculus, and on these grounds the right kidney was explored by a lumbar incision on July 30th, 1900 ; there was nothing of special note connected with the operation. Vomiting commenced a few hours after the operation was performed and persisted almost incessantly up to the time of death, which took place on the evening of August 4th. The temperature fluctuated a little but kept low, and reached $98^{\circ} \mathrm{F}$. before death ; the pulse was very rapid, varying from 120 to 140 per minute. There was no suppression of urine-on the day of death 33 ounces were passed. At the post-mortem examination, which was made on August 5th, I found the stomach to be enormously distended and of cylindrical shape, the lower end being on a level with the iliac crest; the first part of the duodenum was also distended. The contents of the stomach consisted of gas and a considerable quantity of thick green fluid. The intestines, with the exception of the first part of the duodenum, were all somewhat collapsed. There was no obstruction of the pylorus and no definite change of any kind was to be observed in the stomach walls. The recent incision into the right kidney was in process of healing and all the structures around it appeared to be healthy; there was some chronic nephritis of both kidneys

CASE 3. - The patient was a female, aged 40 years, who was admitted into the hospital under my care (in the absence of Dr. Fowler), suffering with deep jaundice, which had come on suddenly with severe pain a few weeks previously. As the diagnosis between gall-stones and malignant disease was somewhat uncertain it was thought advisable to explore the abdomen; this was accordingly done by Mr. J. Murray on April 30th, 1901, the condition proving to be a growth of the head of the pancreas and a distended gall-bladder the gall-bladder was drained and the wound was sutured. All went perfectly well till May 4th, when the patient passed a restless night and vomited early in the morning of FIG. 1.

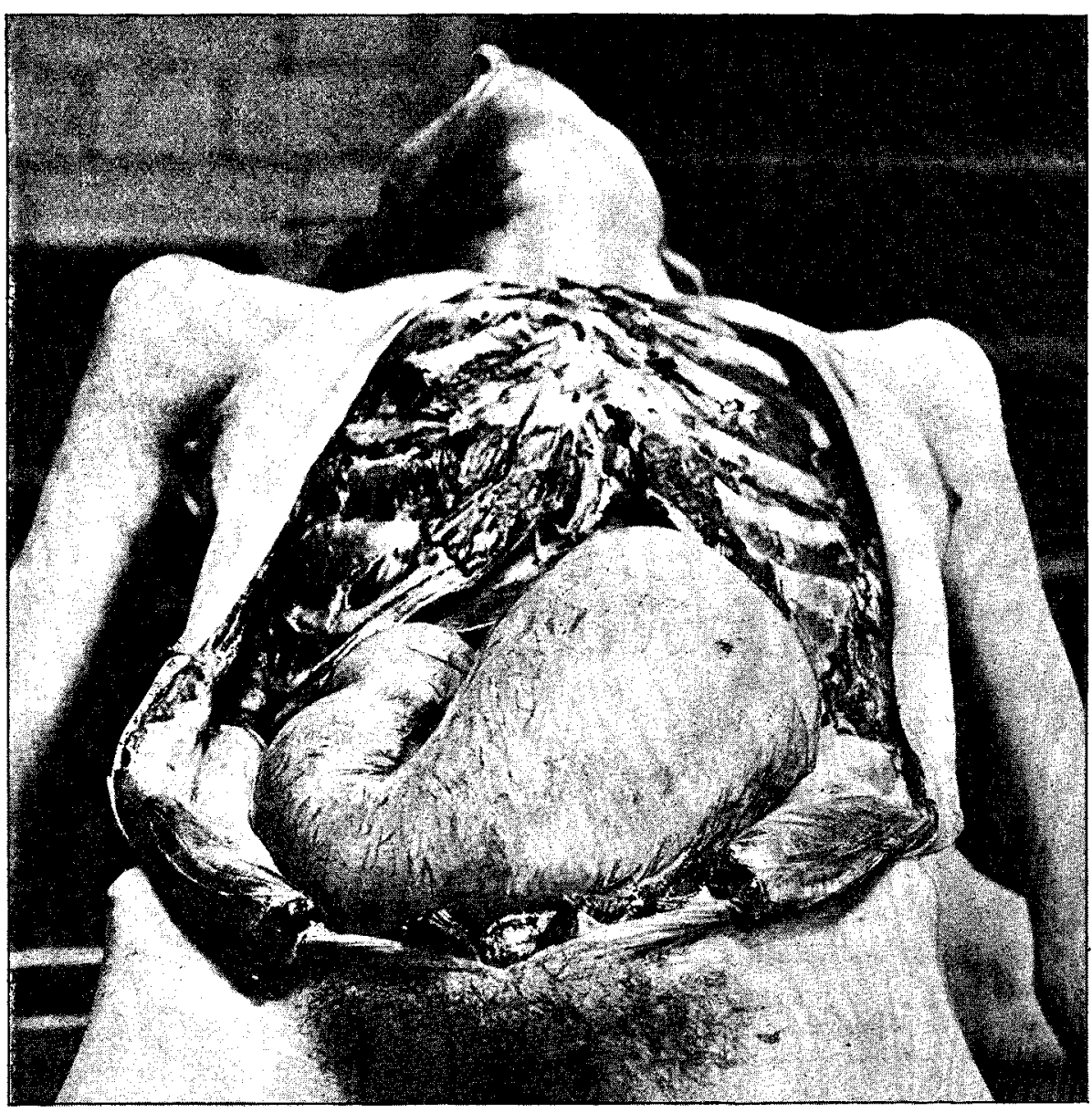

of the stomach complicating lobar pneumonia and pleurisy.

May 5th. She also became very collapsed, but this may have been partially due to some hæmorrhage which occurred in the wound. The vomiting, however, persisted and large quantities of brownish fluid were thrown up; the urine became scanty and the temperature was subnormal before death, which took place on the 9th. 'The post-mortem examination showed the stomach to be greatly distended, but chiefly with gas, there being only a small quantity of greenish fluid present. The stomach had the same cylindrical appearances as in the other cases, but was not quite so large as any of the other three which I have met with. There was a hard tumour of the head of the pancreas, but it was not very prominent, and as far as could be seen it had not caused any definite obstruction to the pylorus, nor was any obvious dilatation of the stomach noted when the abdomen was explored.

The next case is one in which acute dilatation occurred as a complication of pleurisy and pneumonia.

CAsE 4.-The patient, a fermale, aged 24 years, was admitted into the hospital under the care of Dr. Fowler on June 26th, 1901. She was first taken ill on the 24th, and pre viously to that she had been in good health. On admission 
there were signs of consolidation over the lower lobe of the right lung and also well-marked signs of pleurisy on the same side. The next morning (the 27 th) there were some improvement and no signs of any extension of the disease ; later in the day, however, there were pain and friction in the left side and at 1 P.M. the patient suddenly vomited The romiting continued incessantly from $1 \mathrm{P} . \mathrm{M}$. on the 27th till $6.30 \mathrm{~A} . \mathrm{M}$. on the $28 \mathrm{th}$, and then ceased till $1.5 \mathrm{P} . \mathrm{M}$. the same day, when it re-commenced and continued till death, which took place at $2 \mathrm{~A}$. M. on the 29 th-i.e., about 36 hours after the vomiting first began. The vomit was of a dark greenish colour, and large quantities were brought up without any violent effort. 'The abdomen was very carefully examined on the $28 \mathrm{th}$, but no distension was observed until 3 P.M. of that day. The urine was passed in usual quantities throughout the illness, but it may here be mentioned that at the post-mortem examination the bladder was perfectly empty. At the post-mortem examination the stomach was enormously distended and reached down to the pubes (vide Fig. 1). The stomach contained about 35 ounces of dark greenish fluid, and the mortuary attendant informed me that a large quantity had escaped by the mouth when the body was being removed. On relieving the stomach of its contents it rapidly shrank, and in a few minutes it had the appearance of being but little larger than normal, and no one seeing it would have thought that it could have been so enormously dilated only a few minutes before; the stomach walls appeared to be perfectly healthy. The intestines were collapsed, apparently from compression; there were no other abnormalities in any of the other abdominal organs except that the liver was rather larger than normal. In the thorax the lower lobe of the right lung was consolidated and in a condition of red hepatisation ; there was no pneumonia elsewhere. Both pleuræ were extensively covered with a thick yellow exudation, which on the left side was particularly marked over the base of the lung where it rested on the diaphragm. some surgical operation, which may or may not be connected with the abdomen. In the case recorded by Mr. Morris, which has already been referred to, the operation consisted in the removal of some necrosed bone from the foot; the patient began to vomit about an hour after the conclusion of the operation and brought up quantities of thin, greenish fluid almost continuously until death took place two days afterwards. The accompanying table shows the associations which have been observed between acute dilatation of the stomach and other lesions and surgical operations.

From this table the cases may be conveniently arranged in the following groups: (1) those in which the dilatation occurred without any apparent cause, and in which, after death, no other lesion was found (Case 2 and Case 3 ) ; (2) those in which after death some other lesion has been found (Cases 1, 4, 7, 9, and 10); and (3) those in which the dilatation has followed some surgical operation and in which after death no other lesion has been found (Cases 5. 6, and 8). In two cases there was some surgical interference as well as another lesion found after deathviz., in Case 7 , in which a tube was passed into the stomach, and in Case 9, in which the abdomen was explored; and although these operations may have had a certain amount of influence in determining the onset of the conclition there can, I think, be little doubt that the predommant factor was the growth in each, which, as will be seen later, produced the effects by implicating surrounding nerve structures. I may here mention another case, of which Mr. Henry Morris has kindly given me the notes, where the dilatation followed an operation. The patient, a thin weakly man, underwent nephrectomy for polycystic disease of the kidney, after which all the symptoms of acute dilatation set in: the abdomen became unsymmetrically distended and great quantities of fluid were vomited until the time of death. Although there can be no doubt as to the nature of the disease, as no post-mortem examination was obtained I have not included it in the table.

Table of Cases of acute Dilatation of the Stomach.

\begin{tabular}{|c|c|c|c|c|c|c|}
\hline $\begin{array}{l}\text { No. of } \\
\text { case. }\end{array}$ & Author. & Reference. & Sex. & Age. & $\begin{array}{l}\text { Morbid conditions found in } \\
\text { addition to dilated stomach. }\end{array}$ & $\begin{array}{l}\text { Operation (if any) prior to the } \\
\text { onset of symptoms. }\end{array}$ \\
\hline 1 & Hilton Fagge. & Guy's Hospital Reports, 1872-73. & M. & 18 & $\begin{array}{l}\text { Retro-peritoneal abscess com- } \\
\text { municating with duodenum. }\end{array}$ & - \\
\hline 2 & $"$, & $"$ & $\mathbf{M}$ & 30 & Nil. & - \\
\hline 3 & Miller and Humby. & $\begin{array}{l}\text { Transactions of the Patho- } \\
\text { logical Society, vol. iv.; also } \\
\text { quoted by Fagge. }\end{array}$ & F. & 48 & Nil. & - \\
\hline 4 & Hughes Bennett. & $\begin{array}{l}\text { Principles and Practice of Medi- } \\
\text { cine; also quoted by Fagge. }\end{array}$ & M. & 26 & Empyema. & - \\
\hline 5 & Henrỷ Morris. & $\begin{array}{l}\text { Transactions of the Pathologi- } \\
\text { cal Society, rol. xxxiv. }\end{array}$ & M. & 37 & Nil. & Operation upon the foot. \\
\hline 6 & J. F. Goodhart. & ," & M. & 29 & $\begin{array}{l}\text { Nil, except some cedema of } \\
\text { the lungs. }\end{array}$ & Excision of the knee. \\
\hline 7 & Campbell Thomson. & - & M. & 48 & Carcinoma of the pylorus. & $\begin{array}{l}\text { Passage of soft tube into the } \\
\text { stomach. }\end{array}$ \\
\hline 8 & $"$ & - & M. & - & Nil. & $\begin{array}{l}\text { Fxploration of the right kidney } \\
\text { (extra-peritoneal method). }\end{array}$ \\
\hline 9 & , & — & F. & 40 & Carcinoma of the pancreas. & Abdominal exploration. \\
\hline 10 & , & - & F. & 24 & $\begin{array}{l}\text { Pneumonia and extensive dia- } \\
\text { phragmatic pleurisy, the latter } \\
\text { chiefly on the left side. }\end{array}$ & $\longrightarrow$ \\
\hline
\end{tabular}

Acute dilatation of the stomach may arise without any apparent cause whatever, the patient being, as far as one can tell, in ordinary health up to the time of the onset of acute symptoms. This was so in Dr. Fagge's second case, in which the patient died after three days' acute illness, and after death no other morbid condition was found except that of the stomach. Dr. Fagge considered that the actual process of enlargement of the stomach is more gradual and is in the end succeeded by sudden symptoms of great severity; but although this is sometimes the case-as, for instance, in the case $I$ have recorded, where there was obstruction to the pylorus, and possibly also in the case in which there was a tumour of the pancreas-there is no reason whatever to believe that there was any slow dilatation previous to the acute symptoms in the other two cases.

In many cases (vide table) some other morbid condition is fonnd in addition to the dilated stomach, and in other instances the dilatation appears to follow immediately upon
There is yet another group of cases in which in debilitated subjects the ingestion of a large quantity of badly masticated food appears to have been the exciting cause. In a case mentioned by Dr. Walter Broadbent ${ }^{4}$ a man, after tramping about the country for two days without food, and who was therefore very exhausted, partook of a large meal of roast pork, after which he was seized with abdominal pain and vomiting, which in spite of treatment terminated fatally in two days. After death the stomach was found to be enormously dilated, the lower border reaching nearly to the pubes. In a case recorded by Dr. W. H. Dickinson, ${ }^{5}$ dilatation occurred in a child snffering from fatty degeneration of the heart, and after death the stomach, which was greatly distended, was inflated with gas and contained a large quantity of meat and potatoes, which were in lumps with sharp angles and edges, just as they had been cut by the nurse.

4 Medical Magazine, July, 1901

5 Transactions of the Pathological Society of London, vol. xiii. 
The following is a summary of the symptoms and postmortem appearances :-

Distension of the abdomen.-As might be expected, the distended stomach gives rise to a swelling of the abdomen; the swelling is not uniform, but fills chiefly the left half and lower part of the abdomen, the right hypochondrium sometimes appearing to be flattened. This swelling, which is of diagnostic value, is not, however, quite constant, for in the case recorded by Mr. Morris it is stated that the abdomen was retracted, and after death, although the stomach was enormously dilated and occupied almost the whole of the abdomen, its anterior surface was said to be flattened. No doubt the abdominal swelling varies with the vomiting, especially in those cases where there is a large quantity of fluid in the stomach, as in one of Dr. Fagge's cases, where the swelling disappeared after a quantity of fluid had been removed by the stomach-pump. Peristaltic waves of contraction do not seem to have ever been observed in these cases, which, I think, rather opposes the theory suggested by Pepper and Stengel, that spasmodic contraction of the pylorus is the cause of the dilatation.

Vomiting. - Vomiting appears to be a constant symptom and usually large quantities of brownish or greenish fluid are brought up. The fluid is usually thin and watery and is generally vomited without causing the patient any great effort or distress.

Urine. - As a rule the urine becomes very scanty and almost entirely suppressed for the last 24 hours before death. In seven cases in which the condition of the urine is mentioned there was more or less suppression in five, and in three of these it was almost absolute during the last 24 hours of life; in two it is mentioned that a catheter was passed under the idea that there might be retention, but only a few drops of water were drawn off.

General symptoms. - The general symptoms are those of collapse ; the pulse is small and very rapid, the respirations are frequent, and the temperature is low, usually subnormal. There is also great thirst, which is probably accounted for by the excessive vomiting of fluid.

Condition of the stomach. - The appearance of the stomach as seen after death is very characteristic; it is like a tightly distenãed cylinder, shaped like a $\mathrm{V}$ with one limb shorter than the other. The angle between the two limbs formed by the lesser curvature is a very sharp one (vide Fig. 2). The

FIG. 2.

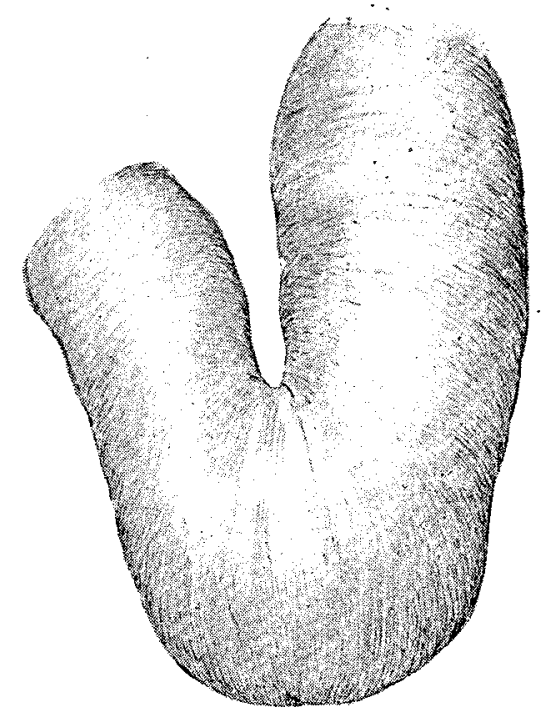

Diagram of shape of stomach in acute dilatation.

walls of the stomach. though so much distended, do not after the stomach has collapsed appear to be much thinned, and, moreover, they retain their elasticity, as shown by the vomiting during life and by the contraction which occurs after death as soon as the contents are let out. There are, in fact, no definite abnormalities to be observed in connexion with the stomach walls.

Condition of the intestines. - The condition of the intestines varies. Usually they are collapsed and have the appearance of having been compressed by the distended stomach ; sometimes parts of them may be distended, as in Dr. Fagge's first case, in which there was some distension of the creum and ascending colon.

The immediate cause of acute dilatation of the stomach probably epends upon some disturbance of the nervous system which gives rise to paralysis of the muscular walls and which also frequently causes excessive secretion into the stomach cavity. The only other explanation which seems within the bounds of possibility is that the distension might be caused by a rapid production of gas within the stomach. This mode of origin was actually suggested in one case in which the patient was known to have drunk two bottles of effervescing lemonade not very long before the acute symptoms began; but Dr. Hughes Bennett, under whose care the case was, rejected the idea and preferred to leave the cause nnexplained rather than to suppose that gas sufficient to distend the stomach so enormously could have been generated by two bottles of lemonade. Neither is there, as far as I can find, any evidence whatever that there has been any undue putrefaction taking place in the stomach in any of these cases and, moreover, this view of the causation would not explain the occurrence of excessive secretion.

In considering the part which the nervous system may take in the production of acute dilatation there are two processes to be taken into account--viz., (1) the dilatation and (2) the increased secretion, and the question at once arises concerning the relationship of these two processes to each other; do they take place independently or is one dependent in some way upon the other? The inclination hitherto seems to have been to look upon the increase of secretion as the primary condition and to regard the dilatation as secondary and immediately dependent upon it. This appears to have been the view taken by Dr. Fagge when, in speaking of his first case, he says that the stomach was paralysed from over-distension and unable to rid itself of its burden. Mr. Henry Morris also took this view; he considered that both dilatation and vomiting were due to excessive secretion, and on these grounds proposed that the disease should be called "acute gastrorrhœa." In support of this view Mr. Morris quoted Moreau's experiments which showed that after a loop of intestine had been isolated by ligatures, and all the nerves passing to it along the mesentery cut, a paralytic secretion took place, and the intestine was found to contain a quantity of fluid which on chemical examination proved to be a very dilute intestinal secretion. Dr. P. H. Pye-Smith and Sir T. Lauder Brunton ${ }^{6}$ have shown that the regulating influence conveyed by the nerves divided in Moreau's experiments arises from some of the ganglia in the solar plexus. As a result of Mr. Morris's paper Dr. J. F. Goodhart ${ }^{7}$ brought forward notes of all the cases of dilated stomach not due to pyluric obstruction observed in the post-mortem room of Guy's Hospital from 1875 to 1882, and in the light of general information obtained from these Dr. Goodhart concluded that "paralysis of the viscus is, if not the determining cause, at any rate an accompanying condition." It is, of course, naturally very difficult to establish the exact relationship between the two conditions, but although they are so often present together, and produced by the same underlying cause, I think that the available evidence shows that they are at any rate distinctly separate processes and that the dilatation is not the mere mechanical result of excessive secretion. In some cases, for instance, there is very little fluid present, the stomach being in such cases almost entirely blown out by gas.

I have recently had an opportunity of observing a very interesting case in which the stomach appeared to be in an early stage of acute dilatation, and in this instance there was no fluid at all, and only a very slight trace of semi-solid, almost completely digested food. The patient was an old woman who died almost immediately after the conclusion of a severe operation upon the lower jaw, and at the postmortem examination the stomach was distended with gas and had the cylindrical sausage-shaped appearance which is so typical in the more advanced cases. The appearance of the stomach in this case is seen in Fig. 3, which is taken from a sketch made at the time. The stomach, though much distended (it measured about nine inches in length in the longer limb and about seven inches at its greatest circumference), was nothing like the size which the others I have met with reached; but naturally there must be an early stage of the condition, and this case, I believe, is an example of such. This case, then, as far as it goes, tends to show that the distension may take place

6 Reports of the British Association for the Advancement of Science, 1874 and 1875.

7 Transactions of the Pathological Society of London, vol. xxxiv. 
independently of the secretion, and some information regarding the relationship between the two processes may, I think, be obtained from the consideration of cases of chronic dilatation which depend upon pyloric obstruction. In many of these there is a very great secretion, just as there is in the acute cases. Osler and Macrae, ${ }^{8}$ for instance, mention a case of dilatation of the stomach due to malignant growth of the pylorus in which on two occasions the stomach was

FIG. 3.

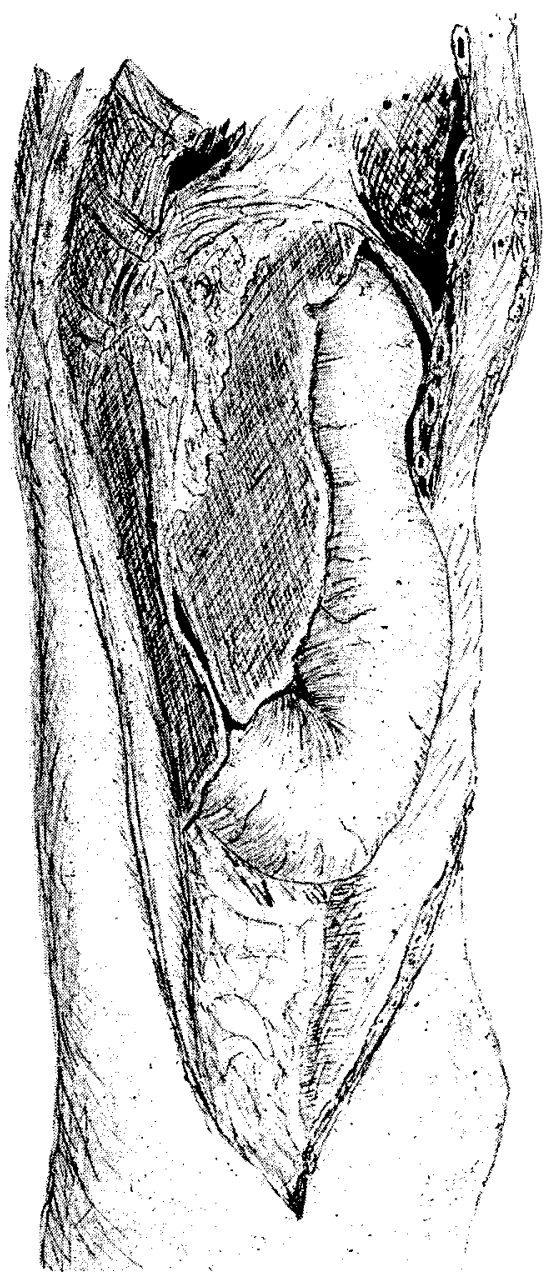

Appearance of a stomach which was apparently in an early stage of acute dilatation.

washed and emptied as thoroughly as possible, and for 48 hours afterwards the patient was fed by the rectum and all nourishment by the mouth was stopped. At the expiration of this time, on the first occasion 545 cubic centimetres of fluid were drawn off, and on the second occasion 500 cubic centimetres. In such cases as this the increased secretion is obviously secondary to the dilatation, as it also frequently is in cases of chronic dilatation which are not due to obstruction, and it seems therefore that the increased secretion is an accompaniment of, or a result of, the dilatation rather than a cause of it. The two conditions, there is little doubt, are independent processes which come into action separately or in combination, and it is most likely that their relative importance varies. There can be no doubt that excessive secretion, when present, adds greatly to the gravity of the situation, but there does not seem to be any clear proof that excessive secretion can act as the dilating force unless there is at the same time some paralysis of the stomach walls. The stomach. derives its nerve-supply from the vagi and the splanchnic nerves; stimulation of the vagi gives rise to peristaltic movements, while stimulation of the splanchnic nerves brings the movements to a standstill. Sir Michael Foster, ${ }^{9}$ in speaking of the nervous mechanism of the alimentary canal, says: "We may, therefore, speak of fibres inhibitory of peristaltic movements of the stomach and intestines as passing from the spinal cord through the splanchnic nerves and reaching those organs through the abdominal plexuses." With regard to the nervous mechanism of secretion Sir Michael Foster says: "It, has been suggested that while impulses reaching the stomach

$\checkmark$ Cancer of the Stomach, p. 81

9 Text-book of Physic, Part II., p. 491. along the vagi excite secretion those reaching the stomach along the sympathetic nerves inhibit it; but this has not been satisfactorily proved."

Dilatation of the stomach can probably be produced by the local interference of nerves of the stomach ${ }^{10}$ or it may arise after a shock affecting the general nervous system. Examples of the latter are seen in cases such as that recorded by Mr. Henry Morris, where the dilatation followed an operation upon the foot, while examples of local interference are shown where the disease has followed some lesion in the neighbourhood of the stomach, and it is interesting to note how in Case 9 of the preceding table the onset of the condition appeared to coincide with the spreading of an acute pleurisy to the base of the left lung, which must be in close relationship to the nervous system of the stomach.

As cases of acute dilatation have followed closely upon operations it is necessary to inquire into the possibility of the anæsthetic having some influence in their causation. Mr. Morris considered this question fully with regard to his case and came to the conclusion that the anæsthetic was not to blame, and examination of the other cases does not show any direct evidence that the condition can be traced to this cause; but it would seem quite possible that under certain conditions an anæsthetic might influence the dilatation through its widespread effects upon the nervous system.

Acute dilatation of the stomach though of course very much more rare, is probably closely allied in its causation and nature to the paralytic distension of intestines which frequently occurs after severe abdominal operations, and also in inflammatory conditions of the peritoneum. At present there seems no adequate explanation as to why the intestines should be distended in some cases and the stomach in others, though most likely this difference depends upon differences in reaction to stimulation of different nerve ganglia.

I think that acute dilatation of the stomach, to some extent, is not so rare as supposed, and that if looked for all degrees of severity may $b$ ? found between the slighter forms of dilatation, such as, for instance, are not infrequently noted in acute specific fevers, and the most severe and rapidly fatal cases such as I have described to-night. Treatment of the recorded cases seems to have been of no avail in checking the disease. The most obvious indication in these very severe cases is to relieve the distension of the stomach by means of a tube, but unfortunately, so far, this does not seem to have been followed by any permanent improvement, although it must be said that with the exception of one of Dr. Fagge's cases, in which temporary relief was produced, this mode of treatment does not seem to have received any extensive trial. All nutrition should be administered by the rectum, and the tendency to collapse met by hypodermic injections of strychnine. Some of the more serious symptoms are probably produced by the loss of the large quantities of fluid which are secreted, and this loss should be counteracted by injection of saline solution into the rectum or by transfusion. Lastly, it must be remembered that possibly on some occasions the condition may be a more general one than seems at first sight and that the dilatation of the stomach may be one of the local manifestations of general collapse. Queen Anne-street, W.

\section{THE ACUTE RETRO-PHARYNGEAL ABSCESS OF INFANTS.}

\section{By S. VERE PEARSON, B.A., M.B., B.C. Cantab.}

THE acute post-pharyngeal abscess of infants is not a common complaint, but it is none the less important. This importance lies in the fact that if undiagnosed the case most frequently ends fatally. I have met with two cases of this disease in which tracheotomy was performed for supposed laryngeal diphtheria, one of which proved fatal ; in the other, afterwards correctly diagnosed, the patient recovered. I can

10 Paralysis of the muscular coat of the stomach limited to the pyloric portion and preventing the propulsion of food into the pyloric portion, and preventing the propulsion of food into the duodenum, has been stated to be a cause of dilatation, and Dr. Wilson Fox ("Diseases of the Stomach," p. 215) quotes a case recorded by Andral where there was extensive ulceration of the pyloric region without obstruction and yet extreme dilatation of the stomach Traube attributes such dilatation to destruction of the branches of the pneumogastric nerve. 